\title{
Microstructure and Property of Sn-37Pb Solder Bumps in Ø0.6 mm Ball during Thermal Shock
}

\author{
Guisheng Gan ${ }^{1,2, *}$, Daquan Xia ${ }^{1}$, Xin $\mathrm{Liu}^{2, *}$, Cong Liu ${ }^{1}$, Hanlin Cheng ${ }^{1}$, Zhongzhen Ming ${ }^{1}$, \\ Haoyang $\mathrm{Gao}^{1}$, Donghua Yang ${ }^{1}$ and Yi-ping $\mathrm{Wu}^{3}$ \\ ${ }^{1}$ Chongqing Municipal Engineering Research Center of Institutions of Higher Education for Special Welding Materials and Technology \\ (Chongqing University of technology), Chongqing 400054, China \\ ${ }^{2}$ Ordnance Equipment Research Institute, Chongqing Electromechanical Vocational Institute, Chongqing 402760, China \\ ${ }^{3}$ College of Materials Science and Engineering, Huazhong University of Science and Technology, Wuhan 430074, China
}

$\mathrm{Sn} 37 \mathrm{~Pb}$ solder bumps with $\varnothing 0.6 \mathrm{~mm}$ ball were used to conduct thermal shock test, microstructure and property of solder bumps were investigated. The experimental results have shown that the shear strength of solder bumps was $62.89 \mathrm{MPa}$ after reflow, then dropped to between 47.31 MPa and 50.86 MPa with increasing of thermal shock cycles, but finally reached to $61.96 \mathrm{MPa}$ at 2000 cycles again. Interfacial IMCs were typical scallop-type and loose in the solder bumps, but were serrated and become smoother and compact after thermal shock with 1500 cycles. The IMCs thickness of solder bumps was about $1.80 \sim 3.05 \mu \mathrm{m}$, but the composition of IMCs was $\mathrm{Cu}_{6} \mathrm{Sn}_{5}$ whether thermal shock or not. $1 / 25$ of solder bumps at 200 1000 cycles, $2 / 25$ of solder bumps at 1500 cycles and 3/25 of solder bumps at 2000 cycles were failure respectively. Obvious tearing crack and fiber tissue was observed in the solder bumps of as-received, and then became large after thermal shock, but dimples of solder bumps deepened after thermal shock at 2000 cycles. [doi:10.2320/matertrans.M2018289]

(Received September 3, 2018; Accepted November 26, 2018; Published January 11, 2019)

Keywords: Sn-37Pb, thermal shock, shear strength, failure, tearing crack

\section{Introduction}

BGA components appeared in the 1990s as the product of advanced high density packaging technology. ${ }^{1)}$ The size of these BGA components was growing and the number of component leads was following this trend. The higher the number of component lead, the greater the probability of failure. ${ }^{2)} \mathrm{Sn}-\mathrm{Pb}$ solder has been used for assembling electronics for $>50$ years due to its good soldering properties. ${ }^{3)}$ With continuous concerning on the toxic of element $\mathrm{Pb}, \mathrm{Pb}$-free solder was gradually used to replace traditional $\mathrm{Sn}-\mathrm{Pb}$ solder. ${ }^{4}$ However, during the transition period from $\mathrm{Sn}-\mathrm{Pb}$ to $\mathrm{Pb}$-free solder, mixing of $\mathrm{Sn}-\mathrm{Pb}$ and $\mathrm{Pb}$-free was inevitable occurred in certain products, and in China where $\mathrm{Sn}-\mathrm{Pb}$ solder was still used extensively in certain areas especially. Correspondingly, understanding reliability of $\mathrm{Sn}-\mathrm{Pb}$ solder joints was very important, and further studies were needed.

The impact reliability of solder joints has been one of the critical concerns due to the failure of joints in portable electronic products under thermal shock. ${ }^{5-9)}$ Board level test method and component level test method were used to evaluate the impact strength of solder joints under high strain rate condition. ${ }^{10,11)}$ Compared with the board level test method, the impact shear test for the single solder bump was more convenient and economical, and was actively pursued by the industries. ${ }^{12-14)}$ Solder joints provided the mechanical and electrical interconnect between the package and the board in the electronic devices, they were susceptible to failures during thermal shock, but we were probably focusing a lot on $\mathrm{Pb}$-free solder joints and neglecting $\mathrm{Sn}-\mathrm{Pb}$ solder joints. ${ }^{14-16)}$

In this study, thermal shock test between $-40^{\circ} \mathrm{C}$ and $125^{\circ} \mathrm{C}$ was conducted on $\mathrm{Sn}-37 \mathrm{~Pb}$ solder bumps in the BGA

*Corresponding authors, E-mail: ggs@cqut.edu.cn; Cathyxin7@163.com package to investigate microstructural evolution and growth mechanism of interfacial IMCs (intermetallic compound) layer. The effects of thermal shock on the mechanical property and fracture behavior of $\mathrm{Sn}-37 \mathrm{~Pb}$ solder bumps were discussed.

\section{Experimental}

The surface of copper coated FR4 board was prepared as shown in Fig. 1. There had 25 pads in each printed circuit board (PCB) which thickness was $1.653 \mathrm{~mm}$. Pad with size of $0.45 \mathrm{~mm}$ spaced at approximately $1 \mathrm{~mm}$ centers, the thickness of copper plating was $41.2 \sim 41.7 \mu \mathrm{m}$ and the solder mask was $19.6 \mu \mathrm{m}$. The resistance of solder bumps was measured by copper wire from the bonding pads at the back in Fig. 2.

$10 \mathrm{vol} \% \mathrm{HCl}$ was smeared on the surface of $\mathrm{PCB}$, and then distilled water and ethanol used to wash and remove residues, finally reoccupied cold wind blow. 25 BGA solder balls of $\mathrm{Sn}-37 \mathrm{~Pb}$ with $\varnothing 0.6 \mathrm{~mm}$ were placed on the pad coated by paste flux, reflow control system of T200N+ was used to determine the reflow profile as shown in Fig. 3. After cooled

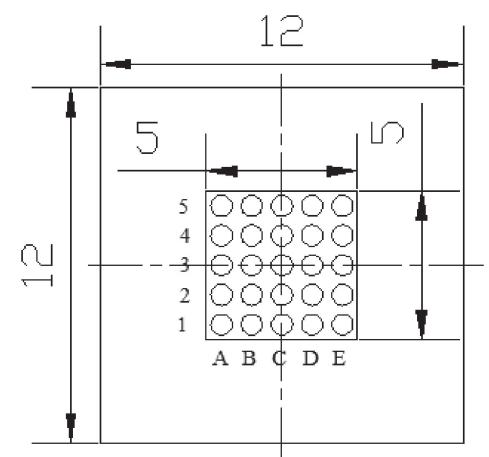

Fig. 1 Size of PCB and distribution of pad. 


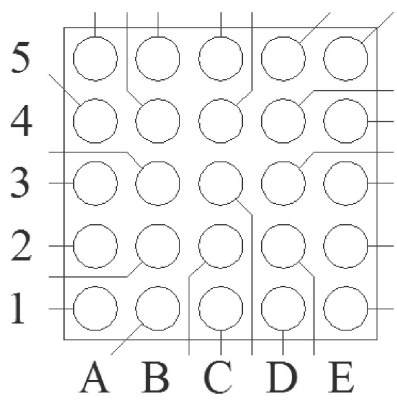

Fig. 2 Copper wire from the bonding pads at the back.

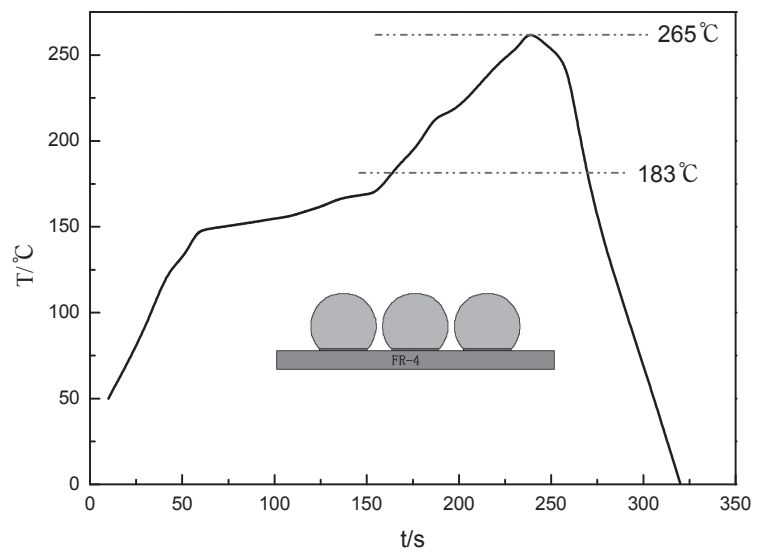

Fig. 3 Reflow profile and solder bumps.

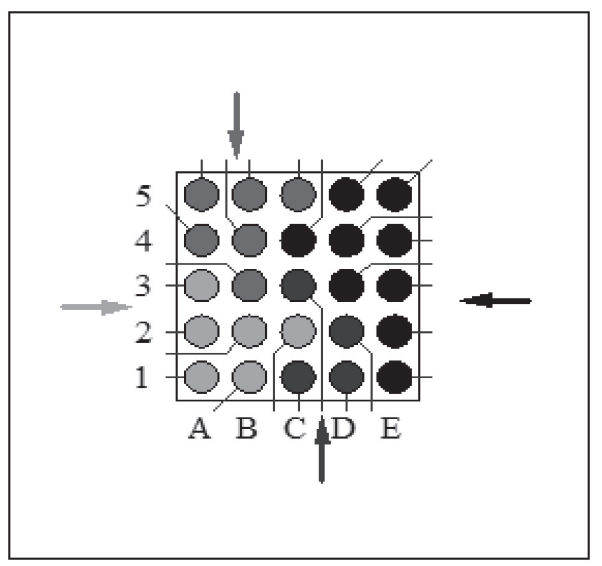

Fig. 4 Shear directions (the direction of the arrow).

to below $100^{\circ} \mathrm{C}, \mathrm{PCB}$ was washed with cleaning agent and blow-dried.

The resistance of solder bumps was measured by milliohmmeter with $\mathrm{VC} 480 \mathrm{C}+$ at first, and then thermal shocked with the temperature profile ranged from $-55^{\circ} \mathrm{C}$ to $125^{\circ} \mathrm{C}$ with $10 \mathrm{~min}$ dwell times respectively. The resistance of solder bumps was reexamined using VC480C + after 200 2000 cycles respectively. The shear strength was performed at room temperature by using a PTR-1102 bond strength tester with shear direction as shown in Fig. 4, and the average shear strength of each parameter was taken from 25 solder bumps.

After sanding and polishing, the specimens were etched in a solution of mixed acids of $3 \mathrm{vol} \% \mathrm{HNO}_{3}+2 \mathrm{vol} \%$

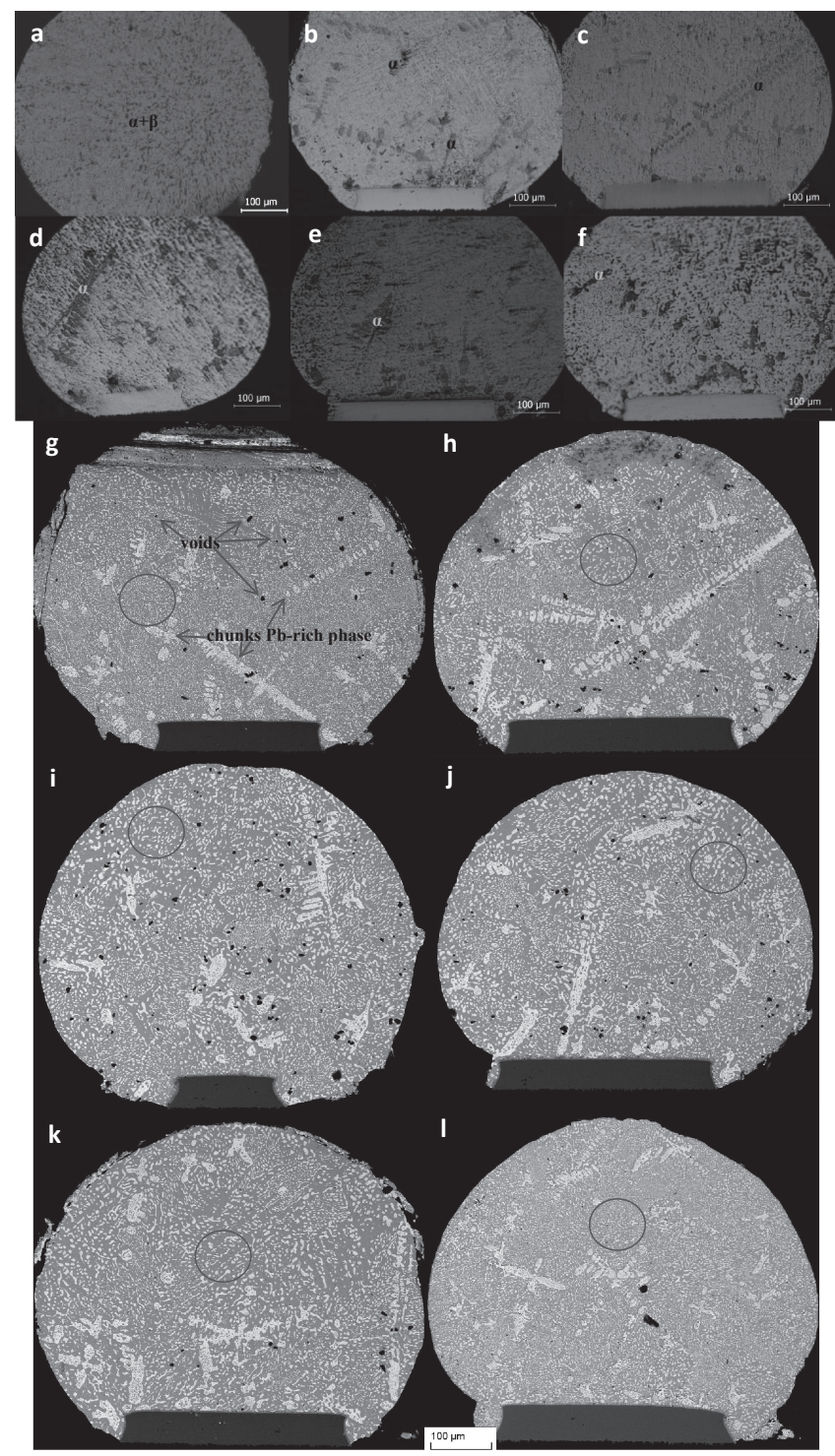

Fig. 5 The morphology of solder bumps at different thermal shock cycles. ((a) solder ball, (b)(g) 0, (c)(h) 200, (d)(i) 500, (e)(j) 1000, (f)(k) 1500, (1) 2000).

$\mathrm{HCl}+95$ vol\% alcohol for $2 \mathrm{~s}$. SEM (ZEISS SUPRA55 scanning electron microscope) was utilized for analysing the interfacial microstructures. The thickness of the interfacial IMCs layer was measured by using Image-pro plus software.

\section{Results and Discussion}

\subsection{Effect of thermal shock cycles on the morphology of solder bumps}

As you can see from Fig. 5(a)-(f), Sn-37Pb solder ball composed of $\mathrm{Pb}$-rich phase $(\alpha)$ and $\mathrm{Sn}$-rich phase $(\beta)$, the distribution was even. Chunks $\mathrm{Pb}$-rich phase $(\alpha)$ were turn out after reflow, most of chunks $\mathrm{Pb}$-rich phase were long shapes after thermal shock, but some were dendrites from the SEM microscopy. At the same time, there were many voids in the solder bumps of as-received in Fig. 5(g), but the number of visible voids increased after thermal shock with 200 and 500 cycles in Fig. 5(h)-(i), and then voids decreased at 1000 cycles in Fig. 5(j). White region was $\mathrm{Pb}$-rich phase and dark region was Sn-rich matrix in the SEM, Pb-rich 

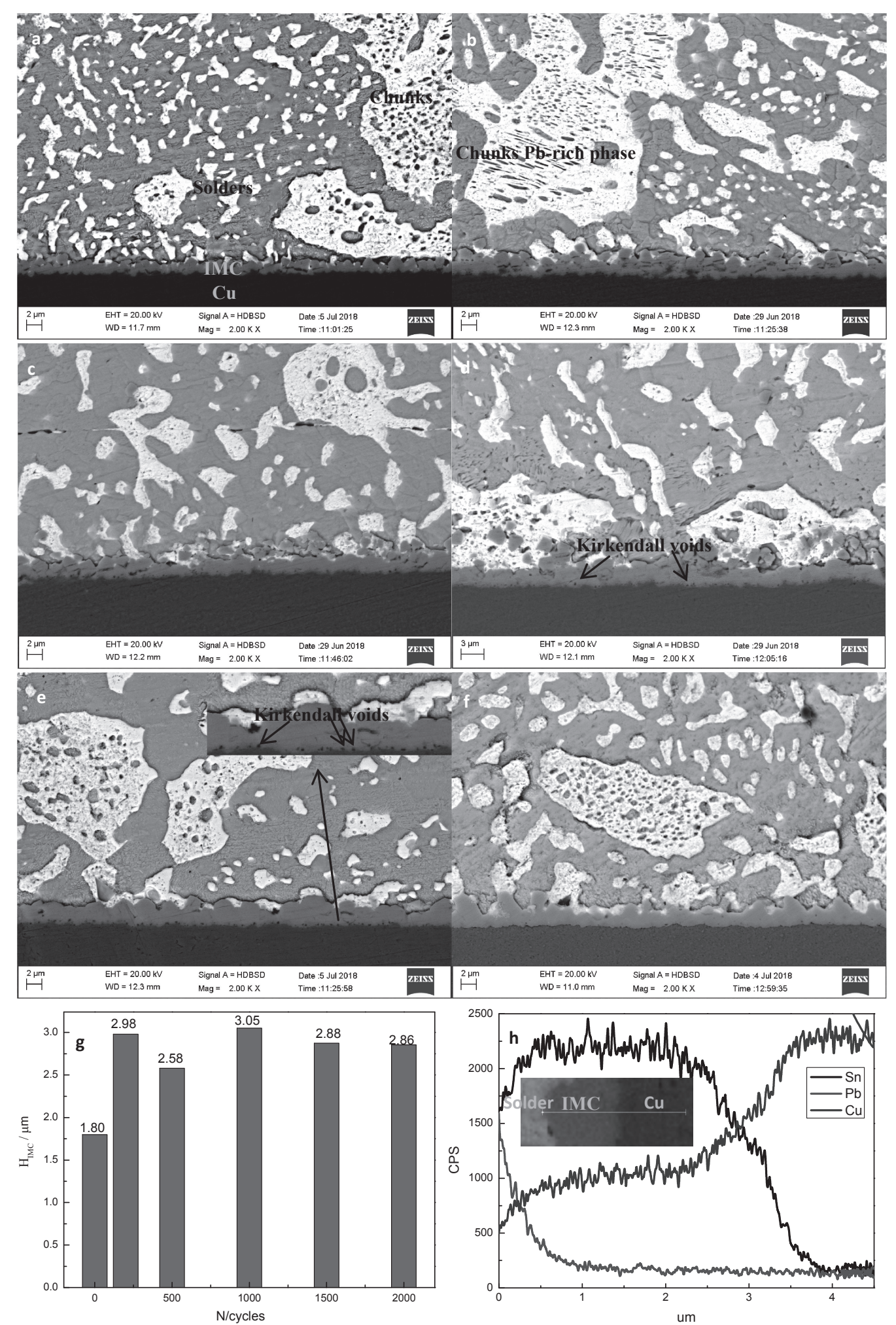

Fig. 6 The morphology (a)(b)(c)(d)(e)(f), the thickness (g) and EDX (h) of interfacial IMCs at different thermal shock cycles ((a) 0 , (b) 200, (c) 500, (d) 1000, (e) 1500, (f) 2000)

phase (as blips in picture) were short and small in the solder bumps of as-received except chunks Pb-rich phase as mentioned above. $\mathrm{Pb}$-rich phase were coarsened with the increase of thermal shock cycles, but $\mathrm{Pb}$-rich phase became spindly after 2000 cycles.

\subsection{Effect of thermal shock cycles on interfacial IMCs of solder bumps}

The morphology and thickness of interfacial IMCs at different thermal shock cycles can be seen from Fig. 6. Interfacial IMCs were typical scallop-type and loose in the solder bumps, but IMCs were serrated and become smoother 

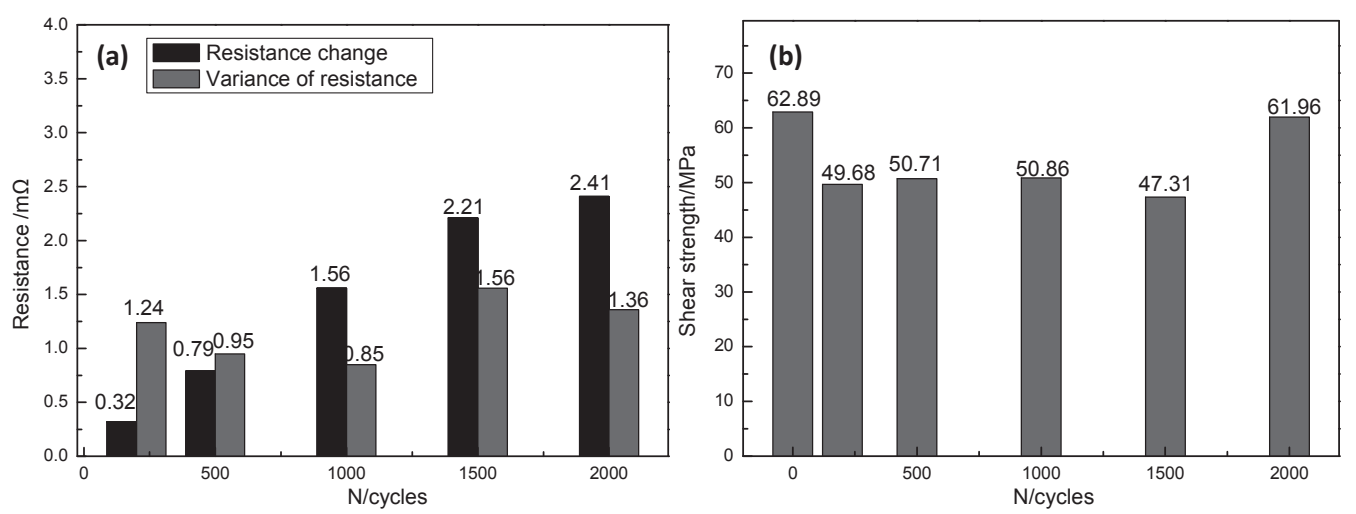

Fig. 7 Resistance (a) and shear strength (b) of solder bumps at different thermal shock cycles.

and compact after thermal shock with 1500 cycles. The IMCs thickness of solder bumps was $1.80 \mu \mathrm{m}$ after reflow, was about $2.58 \sim 3.05 \mu \mathrm{m}$ after thermal shock. Kirkendall voids were only observed at the interface between the $\mathrm{Cu}$ and IMCs at 1000 cycles and 1500 cycles.

Interfacial IMCs ended in coarsening of $\mathrm{Pb}$-rich phase which occurred near the interface, and covered on the intermetallic interface. This phenomenon was related to the growth of the intermetallic layer at thermal shock. For the growth of the $\mathrm{Cu} / \mathrm{Sn}$ intermetallic, $\mathrm{Sn}$ was consumed from the bulk solder, causing enrichment of $\mathrm{Pb}$ close to the interface. The self-diffusion rate of $\mathrm{Sn}$ was lower than the boundary diffusion of $\mathrm{Pb}$, an isolation zone of $\mathrm{Pb}$ was formed due to the $\mathrm{Pb}$-rich phase skewing on the soldering interface which will hinder the further overgrowth of the IMC layer. ${ }^{17-22)}$

There were only a platform in the EDX of interfacial IMCs at different thermal shock cycles. The atomic ratio of $\mathrm{Sn} / \mathrm{Cu}$ both was about $68.1 / 31.9$ after thermal shock with 1500 cycles in Fig. 6(h), the composition of IMCs was $\mathrm{Cu}_{6} \mathrm{Sn}_{5}$ in $\mathrm{Sn} / \mathrm{Cu}$ joint by $\mathrm{Sn}-\mathrm{Cu}$ phase diagram.

\subsection{Effect of thermal shock cycles on resistance and shear strength of solder bumps}

Resistance change of solder bumps before and after thermal shock were $0.32,0.79$ and $1.56,2.21$ and $2.41 \mathrm{~m} \Omega$ at 200, 500 and 1000, 1500 and 2000 cycles respectively in Fig. 7(a). The largest of resistance change in all solder bumps were $25.7 \%, 20.4 \%$ and $23.9 \%, 40.7 \%$ and $27.3 \%$ respectively. Based on the statistics data, 1/25 of solder bumps at $200 \sim 1000$ cycles, $2 / 25$ of solder bumps at 1500 cycles and $3 / 25$ of solder bumps at 2000 cycles were failure respectively because the change ratio of resistance was above $20 \%$ by IPC/JEDEC-9704A. The variances of resistance were $1.24,0.95$ and $0.85,3.71$ and 3.41 at 200 2000 cycles respectively, so our test results were valid and reliable.

Resistivity of $\mathrm{Cu}_{6} \mathrm{Sn}_{5}$ and $\mathrm{Cu}_{3} \mathrm{Sn}$ were 17.5 and 8.92 $\mu \Omega \cdot \mathrm{cm}$ respectively. ${ }^{17)}$ Obviously, the resistance of solder bumps increased significantly with the increasing of thickness of IMC layer. At the same time, the resistance of solder bumps increased at first and then decreased at different thermal shock cycles due to changes in number and size of voids. However, the size of $\alpha-\mathrm{Pb}$ phase and $\beta$-Sn phase also increased at first and then decreased with increasing of thermal shock cycles, the grain boundary area will reduce

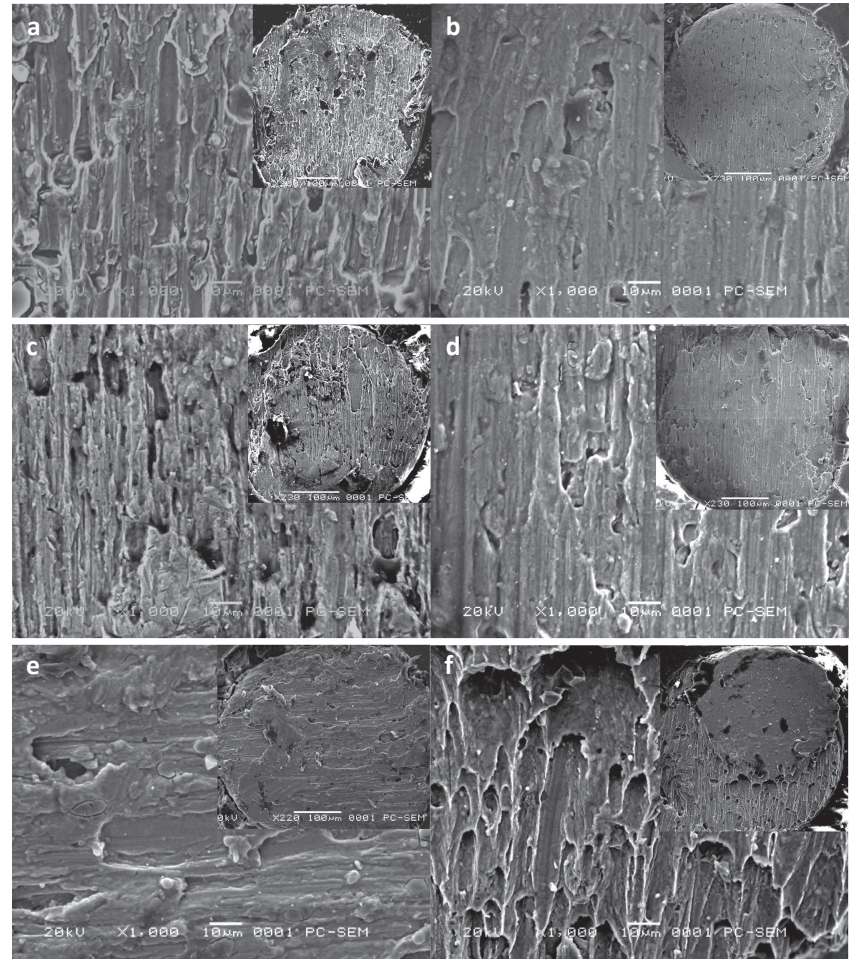

Fig. 8 Fracture morphology of joint at different thermal shock cycles. ((a) 0 , (b) 200, (c) 500, (d) 1000, (e) 1500, (f) 2000).

with increasing of grain size which was conducive to reducing the interconnect resistance.

The mean value of shear strength of 25 solder bumps was 62.89 $\mathrm{MPa}$ in the solder bumps of as-received in Fig. 7(b), then dropped to between $47.31 \mathrm{MPa}$ and $50.86 \mathrm{MPa}$ with the increase of thermal shock cycles, the sharpest contraction at 200 cycles was $24.77 \%$. Finally the shear strength reached to $61.96 \mathrm{MPa}$ at 2000 cycles. With the increase of thermal shock cycles, $\mathrm{Pb}$-rich phase was coarsened and voids increased at first, $\mathrm{Pb}$-rich phase refined and voids decreased secondly. Coarser $\alpha-\mathrm{Pb}$ and voids made the solders more prone to breakage. However, finer $\alpha-\mathrm{Pb}$ can improve the shear strength of solder bumps, for example the solder bumps at 0 and 2000 cycles.

Fracture occurred mainly in solders, the shear fractures of solder bumps were showed in Fig. 8. The fracture presented the parabolic dimple, and its orientation was the same with the shear orientation. Obvious tearing crack and fiber tissue 
was observed in the solder bumps of as-received. Tearing crack became large after thermal shock, but dimples of solder bumps deepened after thermal shock with 2000 cycles.

\section{Conclusions}

(1) With the increase of thermal shock cycles, Pb-rich phase was coarsened and the voids increased at first, $\mathrm{Pb}$-rich phase refined and voids decreased secondly. The shear strength of solder bumps was $62.89 \mathrm{MPa}$ after reflow, then dropped to between $47.31 \mathrm{MPa}$ and $50.86 \mathrm{MPa}$ with the increase of thermal shock cycles, but reached to $61.96 \mathrm{MPa}$ at 2000 cycles again.

(2) Interfacial IMCs were typical scallop-type and loose in the solder bumps, but were serrated and become smoother and compact after thermal shock with 1500 cycles. Kirkendall voids were only observed at the interface at 1000 cycles and 1500 cycles. The IMCs thickness of solder bumps of as-received was $1.80 \mu \mathrm{m}$, and was about $2.58 \sim 3.05 \mu \mathrm{m}$ after thermal shock, but the composition of IMCs was $\mathrm{Cu}_{6} \mathrm{Sn}_{5}$ whether thermal shock or not.

(3) $1 / 25$ of solder bumps at 200 1000 cycles, $2 / 25$ of solder bumps at 1500 cycles and 3/25 of solder bumps at 2000 cycles were failure respectively. Obvious tearing crack and fiber tissue was observed in the solder bumps of as-received. Tearing crack became thick after thermal shock, but dimples of solder bumps deepened after thermal shock with 2000 cycles.

\section{Acknowledgments}

This work was supported by the National Natural Science Foundation of China (Grant No. 61774066), the Innovate Program of Common Special Key Technology in Focus Industries of Chongqing (NO.cstc2016zdcy-ztzx0047 and cstc2016zdcy-ztzx0036), the Scientific and Technological Research Program of Chongqing Municipal Education Commission (NO.KJQN201803701), the Students' research Projects of Chongqing University of technology in 2018 (NO.KLA18001) and College Students Innovation and Entrepreneurship Training Program in 2018 (NO.
2018CX024), and the Research Projects of Experimental Techniques of Chongqing University of technology (NO. SK201708) respectively.

\section{REFERENCES}

1) S. Tan, J. Han, Y. Wang and F. Guo: J. Mater. Sci. Mater. Electron. 29 (2018) 7501-7509.

2) B. Sinkovics and O. Krammer: Microelectron. Reliab. 49 (2009) 573578.

3) S. Cheng, C.M. Huang and M. Pecht: Microelectron. Reliab. 75 (2017) 77-95.

4) F.J. Wang, D.Y. Li, S. Tian, Z.J. Zhang and C. Yan: Microelectron. Reliab. 73 (2017) 106-115.

5) S.H. Tan, J. Han and F. Guo: Microelectron. Reliab. 71 (2017) 126133.

6) R.Y. Tian, C.J. Hang, Y.H. Tian and L.Y. Zhao: Mater. Sci. Eng. A 709 (2018) 125-133.

7) J. Gu, J. Lin, Y. Lei and H. Fu: Microelectron. Reliab. 80 (2018) 2936.

8) A. Sharma, Y.J. Jang, J.B. Kim and J.P. Jung: J. Alloys Compd. 704 (2017) 795-803.

9) O.O. Ogbomo, D.E.H. Amalu, N.N. Ekere and P.O. Olagbegi: Sol. Energy 170 (2018) 682-693.

10) E.H. Wong, S.K.W. Seah and V.P.W. Shim: Microelectron. Reliab. 48 (2008) 1747-1758.

11) B. Zhang, H. Ding and X.J. Sheng: Microelectron. Reliab. 49 (2009) 530-536.

12) J.M. Song, Y.R. Liu, Y.S. Lai, Y.T. Chiu and N.C. Lee: Microelectron. Reliab. 52 (2012) 180-189.

13) C.F. Tseng, C.J. Lee and J.G. Duh: Mater. Sci. Eng. A 574 (2013) 6067.

14) J.X. Wang and H. Nishikawa: Microelectron. Reliab. 54 (2014) 15831591.

15) J.W.C.D. Vries, M.Y. Jansen and W.D.V. Driel: Microelectron. Reliab. 47 (2007) 444-449.

16) M. Spraul, W. Nuchter, A. Moller, B. Wunderle and B. Miche: Microelectron. Reliab. 47 (2007) 252-258.

17) B. Zhou, X.P. Li, Y.F. En, T. Lu, X.Q. He and R.H. Yao: J. South China Univ. Technol. 44 (2016) 8-13 (In Chinese).

18) J.L. Chang, X.Q. Liu and X.M. Xie: J. Funct. Mater. Device 11 (2005) 445-450 (In Chinese).

19) P.L. Hacke, Y. Fahmy and H. Conrad: J. Electron. Mater. 27 (1998) 941-947.

20) J. Zhao: Scr. Mater. 48 (2003) 1277-1281.

21) Y.C. Liang, H.W. Lin, H.P. Chen, C. Chen, K.N. Tu and Y.S. Lai: Scr. Mater. 69 (2013) 25-28.

22) F.Y. Ouyang, K.N. Tu and Y.S. Lai: Mater. Chem. Phys. 136 (2012) $210-218$. 